\title{
MINIMAL OPERATIVE MORTALITY IN PATIENTS UNDERGOING CORONARY ARTERY BYPASS WITH SIGNIFICANT LEFT VENTRICULAR DYSFUNCTION BY MAXIMIZATION OF METABOLIC AND MECHANICAL SUPPORT
}

George E. Cimochowski, MD

Michael D. Harostock, MD

Peter J. Foldes, MD

\begin{abstract}
Between January 1, 1992, and January 23, 1996, 111 consecutive patients with severe left ventricular dysfunction underwent isolated coronary artery bypass grafting. The ejection fraction in these patients ranged from $10 \%$ to $34 \%$ (mean $27.9 \% \pm 5.4 \%$ ); in 18 patients the value was less than $20 \%$. The high operative mortality rate $\mathbf{7 . 6 \%}$ in Society of Thoracic Surgeons database) in this group of patients at high risk was targeted for reduction by provision of, in addition to the usual inotropic support, progressively more intensive metabolic and mechanical support. The metabolic support consisted of triiodothyronine; glucose, insulin, and potassium; aspartate/ glutamate in the cardioplegic solution; and warm-cold-warm/antegraderetrograde-antegrade cardioplegia. Mechanical support included liberal use of the intraalortic balloon pump, use of a new occlusive retrograde cardioplegia catheter, ultrafiltration to remove myocardial depressant factors, and, finally, delayed sternal closure. The operative mortality rate was $1.8 \%$ (2/111). Complications included reoperation because of bleeding $(3.6 \%, 4 / 111)$, mediastinitis $(1.8 \%, 2 / 111)$, and stroke $(0.9 \%, 1 / 111)$ and there were no occurrences of new postoperative acute renal failure $(0.0 \%$, $0 / 111$ ). The intensive care unit stay was $2.2 \pm 0.9$ days with a length of stay in the hospital of $13.7 \pm 22.1$ days. These techniques done before operation, intraoperatively, and postoperatively optimize the milieu of the depressed left ventricle by maximizing perioperative high-energy phosphate bonds; increasing the effectiveness of inotropic agents; unloading the left ventricle by chemical, metabolic, and mechanical support; and removing known myocardial depressant factors, which reduced the operative mortality rate to $1.8 \%$ compared with $7.6 \%$ as reported in the Society of Thoracic Surgeons' database. (J Thorac Cardiovasc Surg 1997;113:655-66)
\end{abstract}

In patients with severe left ventricular failure caused by ischemic cardiomyopathy, the superior long-term survival treatment has been clearly shown to be coronary artery bypass grafting (CABG). ${ }^{1-4}$ Christakis and associates ${ }^{4}$ in a recent article clearly delineated the peculiar operative risk factors found in this selected group of patients as compared with

From Wilkes-Barre General Hospital, Wilkes-Barre, Pa.

Read at the Twenty-second Annual Meeting of The Western Thoracic Surgical Association, Maui, Hawaii, June 26-29, 1996.

Received for publication July 3, 1996; revisions requested August 5, 1996; revisions received Nov. 11, 1996; accepted for publication Nov. 11, 1996.

Address for reprints: George E. Cimochowski, MD, 35 West Linden St., Suite 340, Wilkes-Barre, PA 18702.

Copyright (C 1997 by Mosby-Year Book, Inc.

$0022-5223 / 97 \$ 5.00+0 \quad \mathbf{1 2 / 6 / 7 9 1 8 5}$ those in patients at large undergoing coronary artery bypass and noted that urgency of operation, reoperation, sex, myocardial protection, and age were the greatest predictors of operative death. Of these, only myocardial protection and to a lesser extent urgency of operation, which itself is often dictated by the deteriorating clinical situation of the patient, can be altered. This group of patients with severe left ventricular failure, however, has a high perioperative mortality rate as noted by the Society of Thoracic Surgeons (STS) database, which reported a $7.6 \%$ mortality rate in 26,661 patients from the years 1992 to 1995 . Although operation bestows the best long-term survival benefit in this group of patients as compared with medical therapy, early operative mortality in one major review paper was $5 \%$ to $25 \%$. $^{3}$

During a 4-year period from January 1, 1992, to 
Table I. Mechanical and metabolic support for patients with low EF

\begin{tabular}{lcr}
\hline & $1992-1996$ Usage & 1995 Usage \\
\hline Mechanical & $32.4 \%(36 / 111)$ & $30.0 \%(12 / 40)$ \\
IABP & $56.7 \%(63 / 111)$ & $100.0 \%(40 / 40)$ \\
Ultrafiltration during bypass & $69.3 \%(77 / 111)$ & $100.0 \%(40 / 40)$ \\
Occlusive retrograde balloon catheter & $2.7 \%(3 / 111)$ & $0.0 \%(0 / 40)$ \\
Delayed sternal closure & & $100.0 \%(40 / 40)$ \\
Metabolic & $49.5 \%(55 / 111)$ & $100.0 \%(40 / 40)$ \\
$T_{3}$ & $50.5 \%(56 / 111)$ & $100.0 \%(40 / 40)$ \\
GIK & $100.0 \%(111 / 111)$ & $100.0 \%(40 / 40)$ \\
Aspartate/glutamate & $100.0 \%(111 / 111)$ & \\
Warm-cold-warm/ante-retro-ante cardioplegia & & \\
\hline
\end{tabular}

January 23,1996 , we prospectively analyzed results in a consecutive series of patients with severe left ventricular dysfunction with a mean left ventricular ejection fraction $(\mathrm{EF})$ of $27.9 \% \pm 5.4 \%$ (range $10 \%$ to $35 \%$ ). An integrated approach extending from the immediate preoperative period to 24 hours after operation was progressively instituted to maximize the milieu preoperatively, intraoperatively, and then postoperatively with respect to increasing myocardial energy bonds, continuously unloading the left ventricle, and directly removing myocardial depressant factors (Table I). This series consisted of 111 consecutive patients operated on in one institution by five surgeons but with use of the standardized technique of a single surgeon (G. E. C.).

\section{Methods}

Between January 1, 1992, and January 23, 1996, 1913 patients underwent isolated CABG at Wilkes-Barre General Hospital. A subgroup of 111 patients had an EF of $35 \%$ or less with a range of $10 \%$ to $35 \%$. Data for these 111 patients were prospectively and consecutively gathered for analysis of operative mortality and morbidity. All other patients undergoing CABG with additional procedures such as valve and aneurysm procedures were excluded from the study.

For the sake of the analysis we compared data from our group with data from the STS national database during the same period (1992 through 1995) (all data from the STS obtained through the national database with permission). The STS study group had an EF of $10 \%$ to $35 \%$ with a mean EF of $26.3 \% \pm 7.2 \%$ (Wilkes-Barre General Hospital $27.9 \% \pm 5.4 \%$ ).

Table II is a list of clinical variables analyzed for this study and compared with those of the STS database. Diabetes mellitus included insulin-dependent diabetes and non-insulin-dependent diabetes. Acute myocardial infarction was defined as an event that occurred in the previous 30 days before the operation including both transmural and subendocardial infarcts. A perioperative myocardial infarct was defined as a new $Q$ wave on the postoperative electrocardiogram or creatine kinase $\mathrm{MB}$ levels greater than $10 \%$ or total quantitative number greater than 1000. Renal failure, either chronic or acute, was defined as a creatinine concentration greater than 1.5 $\mathrm{mg} / \mathrm{dl}$. The mortality rate included deaths within a 30-day period after operation that occurred in or out of the hospital. The EF was calculated by the cardiologist via a 30-degree right anterior oblique projection on cineradiography. When appropriate, thallium stress testing with resting reinjection with the use of single-photon emission computed tomography (SPECT) is our standard thallium preoperative test. The dobutamine stress test was done with the aid of esophageal ultrasonography and local anesthesia with use of a low-dose regimen of dobutamine in doses of 5 and $10 \mu \mathrm{g} / \mathrm{kg}$ per minute to assess wall segment motion. Definition of the operation as elective or emergency was determined by the operating surgeon, but emergency operations generally included those done less than 24 hours after the cardiac catheterization or during a clearly deteriorating clinical situation. Cardiogenic shock was defined as persistent hypotension with systolic blood pressure lower than $100 \mathrm{~mm} \mathrm{Hg}$ with a cardiac index less than $2.0 \mathrm{~L} / \mathrm{m}^{2}$ and generally necessitated the use of an intraaortic balloon pump (IABP) to stabilize the patient's condition on the way to the operating room. Coronary artery anatomy was considered significantly compromised when greater than $70 \%$ luminal narrowing occurred in a major vessel, except in the left main artery where narrowing of $50 \%$ was considered significant. Preoperative rhythm disturbances were considered significant if they were ventricular in origin and noted by the surgeon.

The paucity of deaths (2) in this series precluded any statistical analysis of various risk factors or treatment modalities as to their effect on death. All data were collected prospectively by the perfusionists, nurse practitioner, and physicians' assistant and collated on Patient Profiles by Aspen computer program software with an IBM 486 computer. Statistical proportions were compared for the different treatment groups for each clinical variable with either a two-sided $\chi^{2}$ test or a two-sided independent-sample Student's $t$ test; $p$ values were considered significant if less than 0.05 . Values given herein after the plus or minus sign are the standard deviation.

Surgical technique. Patients were brought to the operating room where lines were placed after institution of general endotracheal high-dose narcotic anesthesia. One gram of methylprednisolone was given intravenously at induction of anesthesia. A Swan-Ganz catheter (Baxter Healthcare Corp., Edwards Division, Santa Ana, Calif.) was inserted in each case. The IABP, if needed, was 
Table II. Preoperative data

\begin{tabular}{lccc}
\multicolumn{1}{c}{ Category } & $\begin{array}{c}\text { Study group } \\
(111 \text { patients })\end{array}$ & $\begin{array}{c}\text { STS control group } \\
(26,661 \text { patients })\end{array}$ & $p$ Value \\
\hline EF (\%) & $27.9 \pm 5.4$ & $26.3 \pm 7.2$ & 0.06 \\
Age (yr) & $62.6 \pm 9.9$ & $65.1 \pm 10.2$ & 0.07 \\
Sex & $79.2 \%(88 / 111)$ & $76.8 \%(2,049 / 26,661)$ & 0.55 \\
$\quad$ Male & $20.7 \%(23 / 111)$ & $23.1 \%(6,170 / 26,661)$ & 0.55 \\
$\quad$ Female & $44.1 \%(49 / 111)$ & $35.9 \%(9,575 / 26,661)$ & 0.07 \\
Diabetes & $38.7 \%(43 / 111)$ & $21.8 \%(5,815 / 26,661)$ & $0.00^{*}$ \\
Left main disease & $34.2 \%(38 / 111)$ & $32.0 \%(8,557 / 26,661)$ & 0.63 \\
Acute MI & $33.3 \%(37 / 111)$ & $20.2 \%(5,392 / 26,661)$ & $0.00^{*}$ \\
COPD & $10.8 \%(12 / 111)$ & $6.6 \%(1,774 / 26,661)$ & 0.08 \\
Acute/chronic renal failure & $12.6 \%(14 / 111)$ & $10.7 \%(2,864 / 26,661)$ & 0.53 \\
PVD & $35.1 \%(39 / 111)$ & $11.7 \%(3,143 / 26,661)$ & $0.00^{*}$ \\
Obesity & $2.7 \%(3 / 111)$ & $12.9 \%(3,454 / 26,661)$ & $0.00^{*}$ \\
Repeat operation & $17.1 \%(19 / 111)$ & $19.9 \%(5,313 / 26,661)$ & 0.46 \\
Arrhythmia & $10.8 \%(12 / 111)$ & $11.6 \%(3,102 / 26,661)$ & 0.79 \\
Emergency operation & $5.4 \%(6 / 111)$ & $7.2 \%(1,929 / 26,661)$ & 0.46 \\
CVA & $29.7 \%(33 / 111)$ & $25.1 \%(6,695 / 26,661)$ & 0.26 \\
Congestive heart failure & & & \\
Angina & $5.4 \%(6 / 111)$ & $16.0 \%(4,286 / 26,661)$ & $0.00^{*}$ \\
Stable & $44.1 \%(49 / 111)$ & $65.7 \%(17,531 / 26,661)$ & $0.00^{*}$ \\
Unstable & $50.5 \%(56 / 111)$ & $18.3 \%(4,844 / 26,661)$ & $0.00^{*}$ \\
No angina & & \\
\hline
\end{tabular}

$M I$, Myocardial infarction; $C O P D$, chronic obstructive pulmonary disease; $P V D$, pulmonary vascular disease; $C V A$, cerebrovascular accident. *Statistically significant difference.

generally placed before operation in the catheterization laboratory or after the institution of general anesthesia and placement of the Swan-Ganz catheter. Intravenous administration of nitroglycerin was started immediately after the patient was brought to the operating room and was continued for 24 hours after operation. If the first measured cardiac index was less than $2.0 \mathrm{~L} / \mathrm{m}^{2}$ then inotropes, unloading drugs, and IABP support were instituted in a progressive fashion. Initially drugs such as dobutamine, 1 to $5 \mu \mathrm{g} / \mathrm{kg}$, were given, followed by milrinone or amrinone if the systemic vascular resistance or the pulmonary artery pressure was significantly elevated. If the index was still less than $2 \mathrm{~L} / \mathrm{m}^{2}$, then epinephrine along with IABP support was added. If the EF was less than $20 \%$ before operation serious consideration was always given to insertion of an IABP before operation.

Triiodothyronine $\left(\mathrm{T}_{3}\right)$ was given shortly after the patient was brought to the operating room in a $0.4 \mu \mathrm{g} / \mathrm{kg}$ per minute dose via an intravenous bolus over 10 minutes followed by a second dose of $0.8 \mu \mathrm{g} / \mathrm{kg}$ approximately 10 minutes before the end of bypass and finally a third dose of $0.4 \mu \mathrm{g} / \mathrm{kg}$ divided over 24 hours and given continuously during the next day. Glucose, insulin, and potassium (GIK) were concomitantly used with $T_{3}$ with administration started on entry of the patient to the operating room at a $1 \mathrm{ml} / \mathrm{kg}$ per hour rate with $30 \%$ glucose, 200 units of insulin, and $40 \mathrm{mEq}$ of potassium. Careful monitoring of the glucose level was done in all patients every 20 minutes in the operating room and then every hour in the intensive care unit for 24 hours. After application of the crossclamp the rate of GIK solution administration was reduced to $1 / 3$ $\mathrm{ml} / \mathrm{kg}$ and maintained for 24 hours.
Cardiopulmonary bypass was instituted with use of an ascending aortic cannula followed by a two-stage venous cannula. Cardioplegic solution was given via a multitiered retrograde catheter (Research Medical, Midvale, Utah) placed into the coronary sinus before bypass and an aortic cardioplegia venting cannula for the antegrade portion of the cardioplegia. Venting was done primarily via the aorta and if necessary the pulmonary artery. Nifedipine, $10 \mu \mathrm{g}$ sublingually, was prophylactically given to all patients at the beginning of the operation, again just before removal of the crossclamp, and at any time during the operative procedure when there were significant ST changes. The cardiopulmonary bypass machine was primed with albumin solution and run at $2.4 \mathrm{~L} / \mathrm{min}^{2}$. The internal thoracic artery was taken down with cautery before bypass using neither bone wax nor cautery on the sternum. After the crossclamp was applied, the patient was given standard Buckberg blood cardioplegic solution with an initial dose of warm antegrade solution followed by near continuous cold retrograde infusion and concluding with a warm retrograde/antegrade infusion. During the cold retrograde portion of the cardioplegia the solution was infused continuously with only short pauses during performance of the distal anastomosis. In addition, the right coronary graft was completed first and from then on cardioplegic solution was given continuously in an antegrade fashion into the right graft while simultaneously retrograde infusion was done into the coronary sinus. Other grafts were infused at the discretion of the surgeon. The systemic perfusion temperature was controlled at $34^{\circ} \mathrm{C}$ and no ice, slush, or water was used in the pericardium during the procedure. Retrograde cardioplegic solution administra- 
Table III. Operative data

\begin{tabular}{|c|c|c|c|}
\hline Variable & Study group & $S T S$ & $p$ Value \\
\hline Right coronary bypass & $90.0 \%(100 / 111)$ & $86.6(23,105 / 26,661)$ & 0.29 \\
\hline Emergency operation & $10.8 \%(12 / 111)$ & $9.1 \%(2,451 / 26,661)$ & 0.56 \\
\hline Reoperation & $2.7 \%(3 / 111)$ & $12.9 \%(3,454 / 26,661)$ & $0.00^{*}$ \\
\hline \multicolumn{4}{|l|}{ No. of distal anastomoses } \\
\hline Mean & $3.5 \pm 0.8$ & $3.5 \pm 1.1$ & 1.0 \\
\hline Range & $1-9(110>2)$ & $\mathrm{N} / \mathrm{A}$ & \\
\hline ITA usage & $83.7 \%(93 / 111)$ & $54.5 \%(14,546 / 26,661)$ & $0.00^{*}$ \\
\hline Bilateral ITAs & $18.9 \%(21 / 111)$ & $2.0 \%(544 / 26,661)$ & $0.00^{*}$ \\
\hline \multicolumn{4}{|l|}{ Cardiopulmonary bypass } \\
\hline Crossclamp time (min) & $58.5 \pm 23.6$ & $63.0 \pm 29.5$ & 0.14 \\
\hline Cardiopulmonary bypass time (min) & $107.6 \pm 44.3$ & $109.1 \pm 45.2$ & 0.74 \\
\hline Time cardioplegia running during crossclamp (\%) & 70.1 & $\mathrm{~N} / \mathrm{A}$ & \\
\hline Perfusate temperature $\left({ }^{\circ} \mathrm{C}\right)$ & $34 \pm 1$ & $29.5 \pm 3.1$ & $0.00^{*}$ \\
\hline Inotropes & $50.4 \%(56 / 111)$ & $59.6 \%(15,903 / 26,661)$ & $0.04^{*}$ \\
\hline \multicolumn{4}{|l|}{$\mathrm{IABP}$} \\
\hline Preoperative & $20.7 \%(23 / 111)$ & $16.3 \%(4,360 / 26,661)$ & 0.21 \\
\hline Intraoperative & $9.9 \%(11 / 111)$ & $8.4 \%(2,262 / 26,661)$ & 0.59 \\
\hline Retrograde catheter perforations & $0.0 \%(0 / 111)$ & $\mathrm{N} / \mathrm{A}$ & \\
\hline
\end{tabular}

$N / A$, Not available; ITA, internal thoracic artery.

*Statistically significant difference.

Table IV. Postoperative complications in patients with low EF

\begin{tabular}{lccc}
\hline \multicolumn{1}{c}{ Category } & $\begin{array}{c}\text { Study group } \\
(11 \text { patients })\end{array}$ & $\begin{array}{c}\text { STS control group } \\
(26,661 \text { patients })\end{array}$ & $p$ Value \\
\hline Operative mortality & $1.8 \%(2 / 111)$ & $7.6 \%(2,035 / 26,661)$ & $0.02^{*}$ \\
Operative mortality without reoperations & $0.9 \%(1 / 108)$ & $6.7 \%(1,557 / 23,207)$ & $0.01^{*}$ \\
Reoperation because of bleeding & $3.6 \%(4 / 111)$ & $2.9 \%(788 / 26,661)$ & 0.69 \\
Deep sternal wound infection & $1.8 \%(2 / 111)$ & $0.8 \%(213 / 26,661)$ & 0.24 \\
Stroke & $0.9 \%(1 / 111)$ & $2.2 \%(3,964 / 26,661)$ & $0.00^{*}$ \\
Renal failure & $0.0 \%(0 / 111)$ & $4.5 \%(1,200 / 26,661)$ & $0.02^{*}$ \\
ICU length of stay (days) & $2.2 \pm 0.9$ & $\mathrm{~N} / \mathrm{A}$ & $10.2 \pm 16.7$ \\
Postop. length of stay (days) & $13.7 \pm 22.1$ & & $0.02^{*}$ \\
\hline
\end{tabular}

$I C U$, Intensive care unit; $N / A$, not available.

*Statistically significant difference.

tion pressure was maintained at less than $40 \mathrm{~mm} \mathrm{Hg}$ with a flow rate ranging from 100 to $280 \mathrm{ml} / \mathrm{min}$.

After the completion of all distal anastomoses the patient was warmed systemically to $37^{\circ} \mathrm{C}$ while warm cardioplegic solution followed by warm blood was given by the retrograde followed by the antegrade method. The crossclamp was then removed. In reoperations all proximal grafts were placed during the initial crossclamp period. Ultrafiltration was used immediately after the institution of bypass with an Amicon, Minn Tech, or, most recently, Research Medical filter and stopped at the termination of bypass. In patients who had renal failure before the operation, continuous dialysis was also done with the ultrafiltration using counter current dialysate to allow both ultrafiltration and dialysis simultaneously. Administration of $\mathrm{T}_{3}(0.4 \mu \mathrm{g} / \mathrm{kg})$ and GIK was then continued for 24 hours. Finally, if myocardial edema precluded closure of the chest, the chest was left open with either closing of the skin or use of a sterile Steri-drape dressing, and at the earliest possible time, usually the second day after the operation, an omental transfer was done followed by closure of the sternum. Atrial-ventricular pacing wires were routinely inserted.

\section{Results}

Data were analyzed from 111 consecutive patients with a mean age of $62.6 \pm 9.9$ years (range 36 to 83 years) (Tables II, III, and IV). There were 88 male and 23 female patients. Preoperative risks included diabetes in $44.1 \%$ (49/111), left main disease in $38.7 \%(43 / 111)$, acute myocardial infarction in $34.2 \%$ (38/111), chronic obstructive pulmonary disease in $33.3 \%$ (37/111), and acute or chronic renal failure in $10.8 \%(12 / 111)$. Emergency operation was necessary in $10.8 \%(12 / 111)$ of the patients. The internal thoracic artery was used in $83.7 \%(93 / 111)$ and bilateral thoracic arteries in $18.9 \%(21 / 111)$. 
The mean number of grafts placed was $3.5 \pm 0.8$ per patient. An IABP was placed prophylactically in $20.7 \%(23 / 111)$ of patients in this series. In 17 of the 23 in whom an IABP was placed prophylactically, insertion was done in the catheterization laboratory. Cardiogenic shock was present in $6.3 \%(7 / 111)$.

The operative mortality rate was $1.8 \%(2 / 111)$. One patient (EF 32\%) died of ventricular tachycardia and the second (EF 34\%) of progressive renal failure early in the series. Morbidity consisted of bleeding that necessitated reoperation in $3.6 \%$ (4/ $111)$, mediastinitis in $1.8 \%(2 / 111)$, and stroke in $0.9 \%(1 / 111)$. No episodes $(0.0 \%, 0 / 111)$ of new postoperative acute renal failure occurred. The length of stay in the intensive care unit was $2.2 \pm 0.9$ days with a total hospital stay of $13.7 \pm 22.7$ days. There were no significant complications noted from the $T_{3}$ infusion or the GIK infusion. There were $0.0 \%(0 / 111)$ perforations of the coronary sinus with use of the new multitiered retrograde coronary sinus catheter and there were no complications related directly to the IABP or to the delayed sternal closure. Finally, ultrafiltration was done without any difficulty and long-term dialysis was reinstituted on the second postoperative day or as needed.

\section{Discussion}

Selection of patients. Primarily, patients who had well-defined anatomic targets were selected for operation (Table V). Two or more major vessels supplying significant portions of viable muscle had to be present. In the most severe cases (EF less than $20 \%$ ) good targets outweighed a poor EF especially if the poor EF was thought to be caused by severe global ischemia, that is, left main coronary artery obstruction. Other factors included positive findings on a thallium stress reinjection SPECT study and, most recently, a positive result on an esophageal dobutamine echocardiographic stress test. ${ }^{5-10}$ Considering that $50.5 \%(56 / 111)$ of the patients had no angina, decreased left ventricular function without angina was not a contraindication to our offering the patient an operation. Indeed, if other factors were favorable, we were inclined to offer coronary bypass to patients with symptoms of congestive heart failure, as have others. ${ }^{1,2,4,11}$

In the absence of angina and when the patient has a very low EF one should consider performance of a stress redistribution thallium or dobutamine stress test to discern viable functioning or hibernating myocardium. ${ }^{7-9}$ Thallium SPECT stress reinfusion testing was done in 25 of the 111 patients in whom
Table V. Ideal criteria for operation with low $E F$

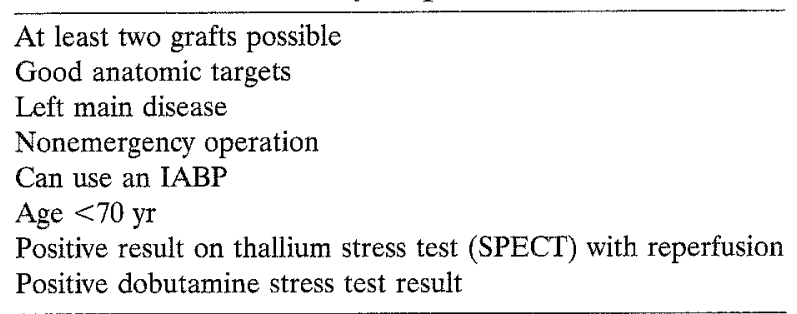

we were concerned about adequate viable myocardium. One should not deny surgical therapy simply on the basis of the presence of an akinetic segment that has a nonfilling defect on the reinjection phase of thallium SPECT scanning (the so-called fixed defect). Zarich and colleagues ${ }^{7}$ eloquently demonstrated that $43 \%$ of fixed defects on thallium reinjection scanning showed improved wall motion after operation, with improvement either to normal kinetic motion or hypokinetic motion. Alfieri and coworkers $^{8}$ clarified the results of dobutamine stress tests on fixed akinetic segments by showing $98.8 \%$ (89/90) of akinetic segments normalized after operation if wall motion improved on the dobutamine echocardiogram. The functional testing ability of the dobutamine echocardiogram provides information on wall motion reversibility in addition to determining wall motion viability. Although positive emission tomography scanning with F18 glucose is unquestionably the gold standard for determining viable myocardium, even it does not dictate whether viable muscle is contracting muscle. ${ }^{8}$

Rationale for the metabolic and mechanical adjuncts. A successful surgical procedure on severely dysfunctional myocardium must rely on adjuncts not necessary in routine CAGB operations such as those in patients with EFs greater than $35 \%$. The chronically ischemic heart is definitely at risk for low output syndrome in the immediate postoperative period. Cardiopulmonary bypass and cardioplegia, which are necessary for the performance of precise coronary bypass grafting, are in themselves harmful from a variety of aspects. ${ }^{12}$ We chose to target these harmful effects before, during, and for 24 hours after operation until the perioperative myocardial depression subsides, primarily by emphasizing unloading as the single best physiologic alteration to improve cardiac performance throughout the perioperative period. Thus in Fig. 1 we compare our mean cardiac index with that in the study of Breisblatt and colleagues, ${ }^{12}$ reported in 1990. That group from the University of Pittsburgh looked at cardiac index for 


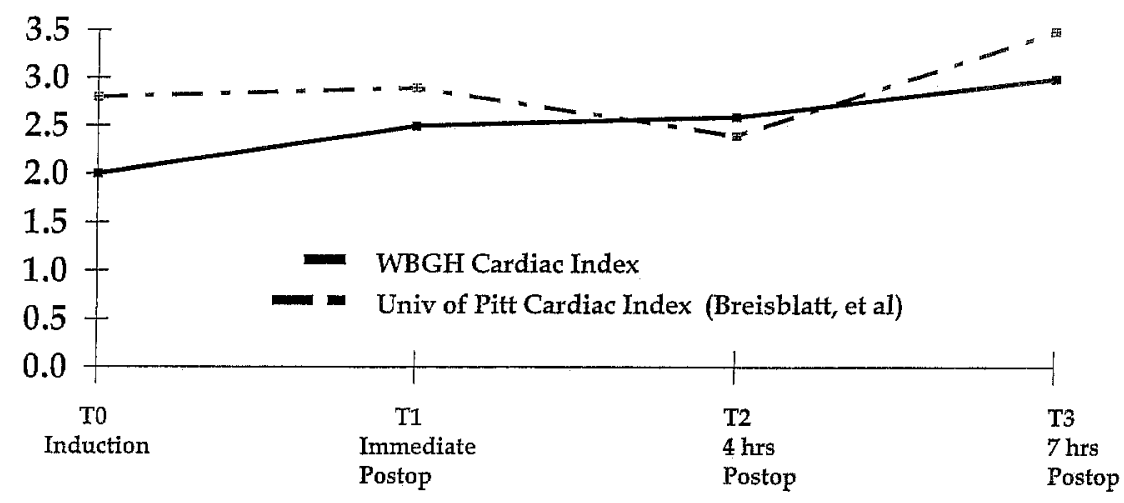

Fig. 1. Continuous postoperative hemodynamic changes (cardiac index in liters per meter squared) in patients undergoing CABG with decreased left ventricular function at Wilkes-Barre General Hospital (WBGH) (EF 27.9\% \pm 5.4\%) versus data from the University of Pittsburgh (Univ of Pitt) as reported by Breisblatt and colleagues ${ }^{12}$ of patients with normal left ventricular function $(E F 58.0 \% \pm 12 \%$ ). Note continuous improvement in cardiac index in patients operated on at Wilkes-Barre General Hospital throughout the perioperative period.

24 hours after routine $\mathrm{CABG}$ in patients with an $\mathrm{EF}$ of $58.0 \% \pm 12 \%$. Significantly, they noted a trough at 4 hours that was not present in our group, as shown in Fig. 1. In contrast, cardiac index values in our patients, despite a markedly lower EF, progressively rose throughout the perioperative period as a result of deliberate attention to reducing afterload, which thus increased the cardiac index.

Before the start of cardiopulmonary bypass, there is time in the operating room to enhance myocardial energy stores and reduce afterload. We began GIK and $T_{3}$ infusion initially at the time the patient was brought to the operating room even before placement of the central lines. GIK solution has been reported for at least 30 years to enhance myocardial function, reduce ischemia after myocardial infarction, and, more recently, improve myocardial performance after cardiac operations including CABG ${ }^{13-15}$ The salutary effects of GIK solution have been reported to be increased adenosine diphosphate and adenosine monophosphate stores in ischemic myocardial tissue. ${ }^{14}$ Two independent controlled studies in patients undergoing cardiac operation reported by Coleman ${ }^{15}$ and Girard ${ }^{16}$ and their associates demonstrated an increase in the cardiac index at 12 and 24 hours in the GIK groups along with decreased inotropic support and reduced time to need for the IABP. ${ }^{15,16}$ Girard and associates $^{16}$ further noted that GIK prevented the usual decrease in $E F$ in the postoperative period by reducing the systemic vascular resistance and also by a primary myocardial effect. They also showed in the same double-blinded, randomized study a significant increase in cardiac index that was especially obvious in the depressed ventricle with the cardiac index increasing after operation by $35 \%$ with a twofold decrease in inotropic support and rhythm disturbances. ${ }^{16}$ Most recently, Lazar and colleagues ${ }^{17}$ in an animal investigation showed that GIK infusion in the acutely ischemic myocardium reduced tissue necrosis, improved wall motion scores, and reduced tissue acidosis in the ischemic myocardium as compared with results in control animals. We extended the treatment from 1 hour before operation to 24 hours after operation because of the significant cost/benefit ratio without an increase in any complications. Simultaneously with GIK therapy, we instituted $\mathrm{T}_{3}$ therapy before operation in accordance with the investigations of Walker, Crawford, and Spinale, ${ }^{18}$ who in a study of chronic left ventricular dysfunction experimentally demonstrated an improved responsiveness to inotropic stimulation. Also, Katz and associates ${ }^{19}$ noted that the effectiveness of $T_{3}$ is blunted by the presence of heparin; therefore, our rationale for doubling the dose of $T_{3}$ before the end of bypass is that the patient is still heparinized. The final dose that we use, which is divided over 24 hours, is delivered during a nonheparinized state and thus we revert to a dose of 0.4 $\mu \mathrm{g}$ divided over 24 hours. DiPierro and colleagues ${ }^{20}$ recently showed not only that $T_{3}$ enhanced cardiac output in the ischemic model by improving mechanical efficiency, but also that it did so without increasing the myocardial oxygen demand. Klemperer and 


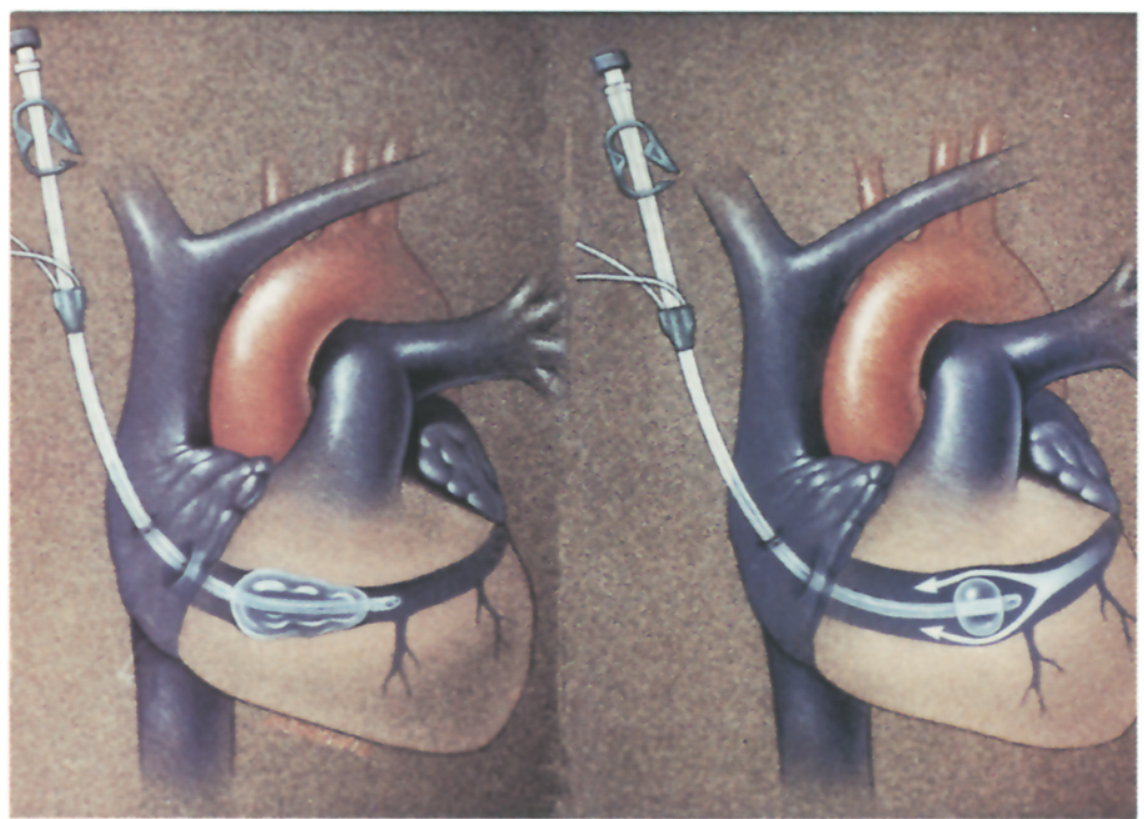

Fig. 2. The usual manual or self-inflating retrograde catheter (right) is often not large enough to prevent reflux around the balloon as opposed to the new three-tiered retrograde balloon catheter (left), which is longer with a larger volume to prevent reflux of cardioplegic solution and to present steal down the posterior descending vein.

Table VI. Complications and costs for mechanical and metabolic adjuncts

\begin{tabular}{llc}
\hline \multicolumn{1}{c}{ Technique } & Complications & Cost \\
\hline GIK & None & $\$ 16.00^{*}$ \\
$\mathrm{~T}_{3}$ & One transient hypertensive episode & $\$ 2,160.00^{*}$ \\
Aspartate/glutamate & None & $\$ 5.00^{*}$ \\
Warm-cold-warm/antegrade-retrograde- & None & No added cost \\
$\quad$ antegrade cardioplegia & & \\
Delayed sternal closure & None & $\$ 2,600.00^{*}$ \\
Retrograde catheter & None & No added cost \\
Ultrafiltration & None & $\$ 95.00$ per filter \\
IABP & None & $\$ 650.00$ per catheter \\
\hline
\end{tabular}

*Average charge per patient.

associates, ${ }^{21}$ in a randomized, double-blind trial in patients with depressed left ventricular function (EF $<40 \%$ ), concluded there was a significant enhancement with $\mathrm{T}_{3}$ of cardiac output and cardiac index with a decrease in the incidence of atrial fibrillation. Finally, Ririe and coworkers ${ }^{22}$ demonstrated increased contractility independent of $\beta_{2}$-adrenergic receptors.

The method of antegrade and retrograde administration of cardioplegic solution with warm induction, followed by near-continuous cold blood infusion with warm reinfusion before unclamping is the Buckberg integrated cardioplegia method and pro- vides aspartate/glutamate to replenish high-energy bonds. ${ }^{23}$ Whereas antegrade and retrograde infusions alone have advantages, the combination of antegrade and retrograde infusion along with the warm-cold-warm method enhances all of the positive aspects of both techniques without detractions. We always administer continuous cold cardioplegic solution in the antegrade manner into the right coronary graft simultaneously with cold retrograde administration of solution to maximize the distribution of the cardioplegic solution to the right side of the heart, which thus facilitates protection of the right side of the heart. 
Table VII. Review of the recent literature for $C A B G$ patients with severely reduced $E F$ since 1990 with mortality least to greatest

\begin{tabular}{|c|c|c|c|c|}
\hline Author & $\begin{array}{l}\text { No. of } \\
\text { patients }\end{array}$ & Years & $E F$ & $\begin{array}{c}\text { 30-Day } \\
\text { mortality }\end{array}$ \\
\hline Cimochowski & 111 & $1992-96$ & Mean $27.9 \%$ & $1.8 \%$ \\
\hline Mickleborough $^{33}$ & 79 & $1982-93$ & Mean $18.0 \%$ & $3.8 \%$ \\
\hline Lansman $^{34}$ & 42 & $1986-90$ & $<20.0 \%$ & $4.8 \%$ \\
\hline Elefteriades $^{2}$ & 83 & $1986-92$ & Mean $24.6 \%$ & $8.4 \%$ \\
\hline Hammermeister ${ }^{35}$ & 251 & $1987-90$ & $<20.0 \%$ & $9.2 \%$ \\
\hline Christakis $^{4}$ & 487 & $1982-90$ & $<20.0 \%$ & $9.8 \%$ \\
\hline $\mathrm{Kaul}^{36}$ & 211 & $1987-92$ & $<20.0 \%$ & $10.0 \%$ \\
\hline Milano $^{3}$ & 118 & $1981-91$ & Mean $25.0 \%$ & $11.0 \%$ \\
\hline
\end{tabular}

Mechanical aspects were also used in our series including the liberal use of the IABP, ultrafiltration to remove myocardial depressant factors, a new occlusive retrograde catheter to minimize coronary sinus leakage, and delayed sternal closure. The use of the IABP in approximately $30 \%$ of the cases per year was relatively stable, although the last year of the study (1995), which had the largest number of patients with poor left ventricular function among the 4 years, saw the least use of the IABP. Although this was not statistically different, it does point out that despite increased numbers of patients the balloon pump has certainly not been used more, but may have been used less, and we attribute this to the positive inotropic and vasodilating effects of $T_{3}$ and GIK. In addition we, like Dietl and associates, ${ }^{24}$ believe that the IABP is far more effective before bypass than it is after bypass. In fact, Dietl and associates $^{24}$ reported the operative mortality rate in patients with prophylactic insertion of the IABP to be $2.7 \%$ when it was inserted before operation versus $11.9 \%$ when it was inserted after operation; therefore we used the IABP in $20.7 \%$ of the patients before operation, in $9 \%$ intraoperatively, and in $0 \%$ after operation.

Ultrafiltration has been used by us and others to remove fluid, especially in patients with congestive heart failure and to dialyze or remove fluid in patients with acute or chronic renal failure. Our philosophy in the past several years has been to use this increasingly, and currently we use it in every patient with a seriously decreased EF to eliminate proinflammatory cytokines. These vasoactive substances are produced by the cardiopulmonary bypass circuit but more recently have been shown to be significantly elevated before operation especially in those patients with poor left ventricular function. ${ }^{25}$ Elimination of cytokines perioperatively has actually been demonstrated in two series of patients. ${ }^{26,27}$ Ultrafiltration may be a much simpler means of removing cytokines and proinflammatory proteins of all sorts as opposed to the use of antibodies or more complex chemical techniques. These proinflammatory cytokines, especially tumor necrosis factor and interleukin-6, have been specifically noted to cause decreased wall motion in patients after CABG. Deng and associates, ${ }^{28}$ in addition, recently reported not only that levels of proinflammatory cytokines were elevated in patients with decreased left ventricular function, but also that there was a strong correlation pertaining to the use of potent inotropic support in the postoperative period and the elevation of these cytokines, especially interleukin-6.

The method of retrograde cardioplegia was first proposed and used in 1955 by Gott and coworkers, ${ }^{29}$ but has recently been revived by the experimental and clinical work of Buckberg, ${ }^{30}$ among others. The lack of occlusion of the coronary sinus has been shown recently to allow a significant reflux of cardioplegic solution into the right atrium, which underscores the need as noted by Menasche ${ }^{31}$ to optimize retrograde delivery of cardioplegic solution. This has further been experimentally investigated by the group at UCLA who showed that there was an increase in the distribution of solution and the nutrients to the right and left ventricles when the coronary sinus was totally occluded ${ }^{32}$ We therefore developed a self-inflating three-tiered catheter, which is larger and longer than the existing retrograde catheters, to prevent the reflux of cardioplegic solution delivered in the retrograde fashion back into the atrium; in addition, it blocks the posterior descending vein so that cardioplegic solution does not return into the right atrium by a retrograde steal via the posterior descending vein (Fig. 2).

Finally, delayed sternal closure was used in three patients to allow immediate postoperative swelling of the acutely failing heart after CABG in patients with an impaired edematous left ventricle. The sternum was closed on the second or third day and any serious infections were avoided by bringing up the omentum from the abdomen during the sternal closure. Table VI summarizes the costs and complications of all adjuncts used.

Conclusion. The cases of 111 consecutive patients who underwent $\mathrm{CABG}$ during a 4-year period with a mean EF of $27.9 \% \pm 5.4 \%$ were prospectively analyzed. Selection of patients included left main coronary artery disease, availability of two or more 
major coronaries that would accept bypass grafts, and elective operation status; patients without angina who had viable myocardium demonstrated by stress SPECT thallium testing or esophageal dobutamine stress echocardiographic examination were included. The mortality rate of $1.8 \%$ was achieved, we believe, by the use of eight adjunctive therapies including four metabolic components $\left(\mathrm{GIK}, \mathrm{T}_{3}\right.$, aspartate/glutamate, and warm-cold-warm/antegrade-retrograde-antegrade cardioplegia) and four mechanical components (IABP, ultrafiltration, a new occlusive retrograde catheter, and, occasionally, delayed sternal closure). Patients with an EF between $10 \%$ and $35 \%$ are unique in the spectrum of patients undergoing CABG, but with careful selection and integrated preoperative and postoperative treatment, excellent postoperative mortality rates can be expected (Table VII).

Sam Merrill, PhD, Wilkes University, Wilkes-Barre, Pa., was the consultant statistician for this study.

\section{REFERENCES}

1. Shapira I, Isakov A, Yakirevich V, Topilsky M. Long-term results of coronary artery bypass surgery in patients with severely depressed left ventricular function. Chest 1995;108: 1546-50.

2. Elefteriades J, Tolis G, Levi E, Mills K, Zaret B. Coronary artery bypass grafting in severe left ventricular dysfunction: excellent survival with improved ejection fraction and functional state. J Am Coll Cardiol 1993;22:1411-7.

3. Milano C, White W, Smith LR, et al. Coronary artery bypass in patients with severely depressed ventricular function. Ann Thorac Surg 1993;56:487-93.

4. Christakis GT, Ivanov J, Weisel RD, et al. Changing patterns of coronary bypass surgery. Circulation 1988;48:592-4.

5. Chan R, Lee K, Calafiore P, Berlangieri S, McKay J, Tonkin A. Comparison of dobutamine echocardiography and positron emission tomography in patients with chronic ischemic left ventricular dysfunction. J Am Coll Cardiol 1996;27: $1601-7$.

6. Depre C, Vanoverschelde JL, Melin J, et al. Structural and metabolic correlates of the reversibility of chronic left ventricular ischemic dysfunction in humans. Am J Physiol 1995; 268(3 Pt 2):H1265-75.

7. Zarich S, Kowalchuk G, Hill T, Kosinski E, Lewis S. Prospective evaluation of viable myocardium by quantitative dipyridamole-thallium-201 scintigraphy and radionuclide ventriculography. Chest 1995;107:335-40.

8. Alfieri O, La Canna G, Giubbini R, Pardini A, Zogno M, Fucci C. Recovery of myocardial function. Eur J Cardiothorac Surg 1993;7:325-30.

9. Arnese $\mathbf{M}$, Cornel $\mathbf{J H}$, Salustri A, et al. Prediction of improvement of regional left ventricular function after surgical revascularization: a comparison of low-dose dobutamine echocardiography with $\mathrm{Tl}$ single-photon emission computed tomography. Circulation 1995;91:2748-52.
10. Kron I. When does one replace the heart in ischemic cardiomyopathy? Ann Thorac Surg 1993;55:581.

11. Townend J, Pagano D, Allen SM, et al. Results of surgical revascularization in ischemic heart failure without angina. Eur J Cardiothorac Surg 1995;9:507-14.

12. Breisblatt W, Stein K, Wolfe C, et al. Acute myocardial dysfunction and recovery: a common occurrence after coronary bypass surgery. J Am Coll Cardiol 1990;15:1261-9.

13. Sodi-Pallares D, Testeili MR, Fishleder MD, et al. Effects of an intravenous infusion of potassium-glucose-insulin solution on the electrocardiographic signs of myocardial infarction. Am J Cardiol 1962;9:166-81.

14. Apstein CS, Gravino FN, Haudenschild CC. Determinants of a protective effect of glucose and insulin on the ischemic myocardium: effects on contractile function, diastolic compliance, metabolism, and ultrastructure during ischemia and reperfusion. Circ Res 1983;52:515-26.

15. Coleman G, Gradinac S, Taegtmeyer H, Sweeney M, Frazier $\mathrm{OH}$. Efficacy of metabolic support with glucose-insulin-potassium for left ventricular pump failure after aortocoronary bypass surgery. Circulation 1989;80(Suppl):191-6.

16. Girard C, Quentin P, Bouvier $H$, et al. Glucose and insulin supply before cardiopulmonary bypass in cardiac surgery: a double-blind study. Ann Thorac Surg 1992;54:259-63.

17. Lazar H, Zhang X, Rivers S, Bernard S, Shemin R. Limiting ischemic myocardial damage using glucose-insulin-potassium solutions. Ann Thorac Surg 1995;60:411-6.

18. Walker J, Crawford F, Spinale F. 3,5,3' Triiodo-L-thyronine pretreatment with cardioplegic arrest and chronic left ventricular dysfunction. Ann Thorac Surg 1995;60:292-9.

19. Katz M, Cohen A, Schwalb H, Segal J, Merin G, Schachner A. Interaction of thyroid hormone and heparin in postischemic myocardial recovery. Ann Thorac Surg 1995;60:1215-8.

20. DiPierro FV, Bavaria JE, Lankford EB, Polidori DJ, Acker MA, Streicher JT, et al. Triiodothyronine optimizes sheep ventriculoarterial coupling for work efficiency. Ann Thorac Surg 1996;62:662-9.

21. Klemperer J, Zelano J, Helm R, et al. Triiodothyronine improves left ventricular function without oxygen wasting effects after global hypothermic ischemia. J Thorac Cardiovasc Surg 1995;109:457-65.

22. Ririe D, Butterworth J, Royster R, MacGregor D, Zaloga G. Triiodothyronine increases contractility independent of $\beta$-adrenergic receptors or stimulation of cyclic- $3^{\prime}, 5^{\prime}$-adenosine monophosphate. Anesthesiology 1995;82:1004-12.

23. Buckberg G. Update on current techniques of myocardial protection. Ann Thorac Surg 1995;60:805-14.

24. Dietl C, Berkheimer M, Woods E, et al. Efficacy and cost-effectiveness of preoperative IABP in patients with ejection fraction of 0.25 or less. Ann Thorac Surg 1996;62: 401-9.

25. Hennein $\mathbf{H}$, Ebba $\mathbf{H}$, Rodriguez J, et al. Relationship of the proinflammatory cytokines to myocardial ischemia and dysfunction after uncomplicated coronary revascularization. J Thorac Cardiovase Surg 1994;108:626-35.

26. Coraim F, Wolner E. Management of cardiac surgery patients with continuous arteriovenous hemofiltration. In: Proceedings of the International Conference on Continuous Arteriovenous Hemofiltration, Aachen 1984. Basel: Karger, 1985:103-10 .

27. Millar A, Armstrong L, van der Linden J, et al. Cytokine 
production and hemofiltration in children undergoing cardiopulmonary bypass. Ann Thorac Surg 1993;56:1499-502.

28. Deng MC, Burkhard D, Erren M, et al. Impact of left ventricular dysfunction on cytokines, hemodynamics, and outcome in bypass grafting. Ann Thorac Surg 1996;62:184-90.

29. Gott VL, Gonzalez JL, Sudhi MN, et al. Retrograde perfusion of the coronary sinus for direct vision aortic surgery. Surg Gynecol Obstet 1957;104:319-28.

30. Buckberg G. Update on current techniques of myocardial protection. Ann Thorac Surg 1995;60:805-14.

31. Menasche P. Experimental comparison of manually inflatable versus autoinflatable retrograde cardioplegia catheters. Ann Thorac Surg 1994;58:533-5.

32. Rudis E, Gates R, Laks H, et al. Coronary sinus ostial occlusion during retrograde delivery of cardioplegic solution significantly improves cardioplegic distribution and efficacy. J Thorac Cardiovasc Surg 1995;109:941-7.

33. Mickleborough L, Maruyama $\mathrm{H}$, Takagi Y, Mohamed S, Ebisuzaki L. Results of revascularization in patients with severe left ventricular dysfunction. Circulation 1994;90(Sup$\mathrm{pl}): \mathrm{I} 640$.

34. Lansman S, Cohen M, Galla J, et al. Coronary bypass with ejection fraction of 0.20 or less using centigrade cardioplegia: long-term follow-up. Ann Thorac Surg 1993;56:480-6.

35. Hammermeister K. Surgery for unstable angina (Department of the Veterans Administration Cardiac Surgery Risk Assessment Program). In: Morrison DA, Serruys PW, editors. Medically refractory rest angina. New York: Marcel Dekker, 1992:199.

36. Kaul T, Agnihotri A, Fields B, Riggins LS, Wyatt DA, Jones $\mathrm{CR}$. Coronary artery bypass grafting in patients with an ejection fraction of twenty percent or less. J Thorac Cardiovasc Surg 1996;111:1001-12.

\section{Discussion}

Dr. Joseph S. Carey (Torrance, Calif.). I would like to congratulate the authors on their great results in this group of patients with difficult conditions. Clearly attention to detail is the most important aspect of getting good results in patients at poor risk. In reviewing the manuscript and comparing this series with our own, several questions came up.

During the same period we had 1309 patients who underwent isolated CABG and 163 of them had poor ventricular function defined as an EF less than 35\%. This would be $12.5 \%$ of the patients as compared with the current report in which there were 111 of 1913 or $5.8 \%$ with poor ventricular function. In the current series only three patients were undergoing repeat $\mathrm{CABG}$ and $10 \%$ underwent the operation on an emergency basis. In our group $16 \%$ were in cardiogenic shock and $25 \%$ were undergoing repeat $\mathrm{CABG}$. Not including patients in these two groups, we had four deaths in 104 patients, two of which were in the older age group. This is a similar mortality rate to that reported by Dr. Cimochowski, and we did not use most of the adjuncts that he has described.

My questions mainly concern the impact of selection, referral patterns, and geographic location on the results. In California we have noted that there is a significant difference in the patient population as compared with the national database in that we have more repeat operations and more emergencies in California and also a higher overall risk profile. It has also been reported that the risk profile of patients in managed-care programs is lower than that of the population at large. In our geographically isolated area, we have two hospitals that are doing cardiac operations and one of them has a consistently higher predicted, as well as observed, mortality. This is primarily because fewer managed-care patients are admitted to that hospital and more acutely ill patients and patients needing emergency operations are admitted to the other hospital.

My first question is this: how are these differences in patient population explained and were some of the patients with shock or repeat operations eliminated from this analysis, or were simply fewer sick patients referred?

Dr. Cimochowski. No patients were eliminated. Actually, during the past 6 years only 12 of our own patients from about 3000 have been reoperated on. We do have a rather locked-in referral base because we are the only heart program in a county of about 500,000 people. I cannot account for the difference in repeat cases other than we are not seeing them in our population very much. I think it is an important issue, though. I looked at the STS database and asked them to eliminate repeat cases and their mortality rate was still $6.7 \%$, which is considerable. I would not hesitate to do a repeat operation in a patient with poor ventricular function, but I think if one is attempting a repeat operation in a patient with an EF less than $20 \%$ there should probably be a cardiac transplant available or a major cardiac assist program. Lastly, we have little managed care in our area, and maybe that accounts for the difference between California and us.

Dr. Carey. I do think that many of the authors' methods are innovative and worthy of note, particularly the evaluation of hemodynamics after induction of anesthesia and the insertion of the balloon pump in a patient who has a low cardiac output before bypass. Also, the early perfusion of the right graft is a good idea. I think the liberal use of inotropic agents before and after operation and ultrafiltration, like all of the other things, are quite important. It is also notable that the authors used so many internal thoracic artery grafts. Overall, I would say the study clearly shows that the careful management of these difficult cases really boils down to carefully controlling all aspects of the care, and the value of each specific adjunct that is used is difficult and probably unnecessary to prove. Clearly just meticulously taking care of these patients with good clinical protocols is the most important thing. The only question I have regarding the method would be related to the expense of the $T_{3}$ and that has more or less been answered. My final question would be whether the authors have looked at the late EF results: have any of these patients shown improved EFs?

Dr. Cimochowski. No, we have not gotten late results yet, but we are in the process of doing so. We are also going to do quality-of-life studies on these patients as well, that is, look at long-term survival and at the EF results.

I think we do have great influence over the anesthesia department, and so when a patient is brought to the operating room, as you point out, with a cardiac index of $1.5 \mathrm{~L} / \mathrm{m}^{2}$, the anesthesiologists immediately start administration of these drugs and they progress up the ladder (in fact, a femoral line is placed in all patients), and we will then proceed right to placement of a balloon pump before 
starting the procedure. We do like to start with an index greater than $2.0 \mathrm{~L} / \mathrm{m}^{2}$. If these low $\mathrm{EF}$ procedures are started with an index less than $2.0 \mathrm{~L} / \mathrm{m}^{2}$, the outcome is oftentimes not very good.

I would like to emphasize the use of the internal thoracic artery, too. As you know, Dr. Grover and his group have noted repeatedly that in emergencies, myocardial infarctions, and other circumstances, patients with an internal thoracic artery seem to do better. We use the internal thoracic artery about $83 \%$ percent of the time in these patients and that point has been confirmed.

Dr. Harold Lazar (Boston, Mass.). There are really no controls in this series, so it is kind of difficult to put these good results in some perspective. My first question is whether the authors can tell us what their mortality rate was in the preceding years in this group of patients.

Dr. Cimochowski. I cannot because I have only been at this institution since 1990 . I can tell you that we had very good cases, it seems, the first two years. In 1993, we had 20 cases of poor ventricular function and in 1994 we had 30 such cases. In 1995 , we had 42 , so we have doubled the incidence in the most recent 2 years. I think before that the number of patients in this category was too small to be critically examined.

Dr. Lazar. So in essence you really could have had an operative mortality rate of $3 \%$, but you do not know the answer to that.

My second question is that in $50 \%$ of the patients the authors say that there was no angina present. I was curious as to what the indications were for operation in this group.

Dr. Cimochowski. Twenty-nine percent of the patients had congestive heart failure as the presenting feature. Others had acute myocardial infarctions and no longer had pain, that is, they had a myocardial infarction but after catheterization had no angina. I cannot break down the indications for operation any further than that, but I personally reviewed these charts and there were only $50 \%$ who reported angina.

Dr. Lazar. That leads me to my final two questions. If these patients do not have any pain and they do have low EFs, then obviously long-term follow-up and long-term results are important. I think the question was raised about whether the authors saw any improvement in EF. Can they tell us whether these patients had any improvement, not only in long-term survival, but also in New York Heart Association or Canadian classification?

Dr. Cimochowski. We are working on compiling the long-term results at present.

Dr. Edward Verrier (Seattle, Wash.). I am fairly concerned, because I think that to take this shotgun approach and take a huge number of adjuncts that have potential benefit and apply them to a population in which the physiologic processes are not really delineated is a mistake and dangerous. An IABP has a definite set of risks that are associated with it. The major series from Massachusetts General showed a $21 \%$ incidence of significant complications from balloons. The inappropriate use of $\mathrm{T}_{3}$ also has potential dangers. When we deal with these sick hearts with low EF, there are a myriad of problems that are going on physiologically.

There is a group that has hibernating myocardium, that reset their thermostats: their biochemical machinery is different. They probably do not require much protection and they will get some recovery of function. There are many patients I have operated on who had EFs before operation of $1.4 \%$ who left the operating room receiving hardly any inotropes with an index of 3 because we did the positron emission tomographic scans or other studies before operation and knew that there was some predictable recovery because they had a chronic ischemic state and had reset their thermostat.

To take the authors' approach and just use all of the adjuncts available $I$ think is not cost effective, certainly. It may not be the safest thing as well because complications occur from a variety of the interventions and in a lot of the instances we do not even understand how they work. They may work in one situation because the metabolic machinery is being enhanced and that is going to upregulate it. I would take caution, because I think that many of us achieve similar results to those of the authors without using all of these adjuncts. I have not perfused a right coronary graft in the past 5 years with my retrograde technique and I have never had a patient who could not be weaned from cardiopulmonary bypass because of right ventricular disease. That may be my particular experience, but I think it behooves us to analyze from a physiologic standpoint what we do as surgeons. We are physiologists, as well as simply people who are technicians who take a number of techniques that we have available and apply them.

Dr. Cimochowski. The physiologic basis for all these adjuncts is clearly explained in our paper. I think the word dangerous for our method is a little strong. We certainly think as you do that there are inappropriate uses of the balloon pump, but with this group I do not think the $20 \%$ preoperative and $9 \%$ intraoperative placement rate was inappropriate or excessive. I understand your conclusion concerning the use of multiple adjuncts. They were instituted to address the multitude of abnormal physiologic conditions in this highly selective group of patients. There is not a single randomized study anywhere in the literature with respect to severe left ventricular dysfunction, so I think we are certainly in good company.

Dr. Steven Gundry (Loma Linda, Calif.). I hate to belabor the point but I agree with the last two discussants. First of all, Dr. Lazar pointed out that the authors really do not have a control group. Well, in fact they do have a control group and each patient is his or her own control. At Loma Linda several years ago we decided that if a patient is receiving no inotropic support and breathing on his or her own when brought into the operating room, then if everything is done right he or she ought to leave the operating room receiving no inotropic support and breathing on his or her own, and so that patient is his or her own control.

Now, as we reported at the Pacific Coast Surgical Association meeting last year, we looked at 36 consecutive patients with EFs of less than or equal to $15 \%$ who underwent warm heart operations with the use of continuous retrograde cardioplegia with a simple balloon catheter that was manually inflated. None of these patients required an LABP. Only $10 \%$ of them required any inotropic support. There were no perioperative deaths, and the average time to discharge from the hospital was 6 
postoperative days. That was compared with how they walked in: receiving no inotropes and breathing on their own. I would submit that the additional cost that the authors add to the patient's hospital bill is actually what we charge to do the entire operation in California. I wonder whether they have looked specifically at what these modifications do that is so important in achieving the results that others of us achieve with none of these modifications.

Dr. Cimochowski. We had a large experience with continuous warm retrograde cardioplegia and we were unhappy with it, more so in valve operations than CABG. Specifically, we had three cases of stone heart because either the cardioplegic solution was not adequately delivered because of a perfusion problem or because of a retrograde catheter problem. I personally do not think that warm continuous cardioplegia is a safe method for coronary bypass operations and even less so for valve operations. The STS database, which covers 26,000 patients, showed a mortality rate of $7.6 \%$ with an EF between $10 \%$ and $30 \%$. These 26,000 patients were operated on by American surgeons in the United States. I think it is a fair assumption to say that the mortality rate is not $1 \%$ to $2 \%$ and that overall the average surgeon operating on this group of patients achieves a rate of $7 \%$ to $8 \%$. Our mortality rate in all patients undergoing CABG for the past 2 years was $1.6 \%$ and $1.4 \%$, respectively, but the mortality rate in the low EF group for patients undergoing $\mathrm{CABG}$ was still higher at $1.8 \%$.

I would note that unlike California, which does not publish cardiac operative outcomes, Pennsylvania does. In addition, cost of operation is published and in the most recent publication we were the third least expensive program in the state of Pennsylvania and 3 years ago we were the only program in the state that cost less than the year before. I believe we are as cost conscious as anybody else. The only adjunct that is a luxury is the $T_{3}$, and I guess time will prove whether that is worthwhile.

Dr. James Edgerton (Racine, Wis.). I hesitate to speak after the last couple discussants, but I will commend Dr. Cimochowski for bearing the barbs and trying to bring some objectivity to what many people are anecdotally doing. I am continually impressed, when I go to these meetings and talk in the hallways, by how many people are using $\mathrm{T}_{3}$. I have one or two quick questions about that.

We also have all of our data published. We have one of the lowest average costs per case in the state of Wisconsin and among the lowest mortality rates in Wisconsin and have been using $\mathrm{T}_{3}$. Initially we used it only for salvage cases in which the patient was obviously going to die in the operating room. We were impressed that with it some of the patients were able to be weaned from cardiopulmo- nary bypass. Since that time, we have been using $T_{3}$ in our patients with EFs less than $15 \%$. We use a protocol a little bit different from the authors', but similar. We give a 16 $\mu \mathrm{g}$ bolus when the clamp comes off or when the last distal anastomosis is done and then administer a rapidly tapering infusion. We are doing increasing numbers of these operations with no crossclamp, no arrest, and occasionally no pump. I would wonder, incidentally, whether the authors are going to any of those techniques. We notice differently from the authors that the administration of $\mathbf{T}_{3}$ drops the afterload so considerably low that we are not able to keep nitroprusside or nitroglycerin effective in those patients. It is not at all uncommon to see values of systemic vascular resistance of 400 to 500. I wonder whether the authors have encountered that.

Dr. Cimochowski. To answer somebody else's question about what $I$ think is the most important adjunct, I think GIK and $T_{3}$ are most important for just the reasons you elicited. I did not have enough time to show the systemic vascular resistance data, but our values of systemic vascular resistance consistently decrease from the time the patient is brought to the operating room from about 1000 or 1200 to the 800 dyne range, and they stay there all during the immediate postoperative period. We like that. I think one of the problems is our anesthesiologists. Five of the six trained at different major universities for an extra year of cardiac anesthesia, and every single one of them was taught to discontinue bypass with a mean arterial pressure of 90 to $100 \mathrm{~mm} \mathrm{Hg}$ and concomitant higher values of systemic vascular resistance. We do not do that. We accept a mean arterial pressure that is much less and that is one of the reasons we like $T_{3}$, because afterload in these patients is smoothly, effectively, and continuously controlled from induction of anesthesia through the next day and a few days later. Systemic unloading throughout the perioperative period is a good point to emphasize.

Dr. Edgerton. As a final comment, we have noted that our use of LABPs after we have started our intravenous $\mathrm{T}_{3}$ protocol in patients with EFs less than $15 \%$ is almost zero. We use very few IABPs. I wonder whether they are needed preoperatively. We also looked at the hospital charge for the patient. In our medical center (where there is a setup fee for the balloon, a charge for the balloon, and an hourly monitoring fee for the balloon), the cost of the $\mathrm{T}_{3}$ is considerably less than 24 hours of balloon pumping.

Dr. Cimochowski. During the past year we had the greatest number of cases of poor ventricular function, and yet our use of the IABP went down. As we gain more confidence in our metabolic adjuncts, we will most likely use the IABP less and use the metabolic adjuncts more. 